\title{
Use of Web-Based Videos in a Community Pharmacy to Optimize Inhalation Technique
}

This article was published in the following Dove Press journal:

International Journal of Chronic Obstructive Pulmonary Disease

\author{
Tobias Müller (D) \\ Maike Möller' \\ Christian Lücker² \\ Michael Dreher' \\ 'Department of Pneumology and \\ Intensive Care Medicine, University \\ Hospital RWTH Aachen, Aachen, \\ Germany; ${ }^{2}$ Elsass Pharmacy, Aachen, \\ Germany
}

Correspondence: Tobias Müller Department of Pneumology and Intensive Care Medicine, University Hospital

RWTH Aachen, Pauwelsstrasse 30,

Aachen 52074, Germany

Tel +49 24I 80-89946

Fax +49 24I 80-82I53

Email tobmueller@ukaachen.de

\begin{abstract}
Purpose: Numerous studies have demonstrated that incorrect use of inhalers prescribed to treat airway diseases is commonly observed and is associated with unfavorable clinical outcomes. The aim of the current study was to investigate whether inhalation technique can be improved by the demonstration of short training video sequences provided by the German Airway League.
\end{abstract}

Patients and Methods: Patients filling a script for an inhalator in a community pharmacy were asked to demonstrate their inhalation technique which was rated using specific checklists. Patients not inhaling correctly demonstrated inhaler use again after having viewing the training video.

Results: A total of $229(\mathrm{n}=229)$ patients were included in the study of whom $165(\mathrm{n}=165)$ (72.1\%) made at least one critical mistake when inhaling. Training videos were only demonstrated to patients with incorrect inhaler technique. After having watched the video $80(n=80)$ of $165(n=165)(48.5 \%)$ patients with incorrect inhaler use at baseline demonstrated correct inhalation technique now and the number of critical mistakes decreased significantly $(1[0 ; 1]$ vs $2[1.5 ; 3] ; \mathrm{p}<0.0001)$. Device use was demonstrated by a member of the study team to patients still not inhaling correctly $(n=85)$ resulting in a correct technique in $64(\mathrm{n}=64)(75.3 \%)$ of these patients.

Conclusion: Incorrect device use is still a major problem. Training videos could be an efficient part of a multi-modal approach to improve inhalation technique in clinical practice. Keywords: inhaler use, COPD, asthma, training

\section{Introduction}

Currently, inhaled bronchodilators and corticosteroids are the most important drugs for the treatment of chronic airway diseases such as asthma or chronic obstructive pulmonary disease (COPD), as inhaled drug administration has the advantage of selective drug deposition in the airways thereby allowing a high drug concentration at the target site and limiting systemic side effects. ${ }^{1,2}$ However, an inhaled drug can only be effective if it reaches the targeted airways. Hence, correct inhalation technique is crucial and an association between poor inhalation technique and unfavorable outcomes in patients suffering from different airway diseases has been shown. ${ }^{3-6}$ Nevertheless, problems with inhaler use are commonly observed in clinical practice though this was recognized shortly after the launch of pressurized metered-dose inhalers in the 1960s. ${ }^{7}$ Unfortunately, though several attempts have been made to train patients in the correct use of inhalators there was no improvement over the last 40 years. 8,9

In 2011 the German Airway League initiated the production of short web-based videos which have been filmed and published for all regularly used devices. The 
training material includes videos, spoken text passages, and visual insertion of information covering all the important steps of inhalation therapy. Besides, the videos are freely available in six different languages (German, English, Turkish, Arabic, Russian, and Slovak). ${ }^{10}$ Previously, we were able to show that these training materials were effective in improving the inhalation technique of patients treated in the respiratory outpatient clinic of a university hospital. Of note, improved inhalation technique was sustained over time as demonstrated by a follow-up after 6 weeks. ${ }^{9}$ Similar results were obtained when using these videos to improve inhalation technique in hospitalized COPD patients. ${ }^{11}$

Community pharmacists can have a valuable role in training patients with obstructive airway diseases on correct inhaler technique leading to a significant improvement in clinical outcomes. ${ }^{12}$ Hence, the current study investigated the use of web-based videos for the instruction on correct inhalation technique in a community pharmacy.

\section{Patients and Methods}

\section{Study Design}

This open-label, single-center study was conducted from 3rd December 2019 to 6th March 2020 at a community pharmacy located in Aachen ("Elsass Apotheke"). The study protocol was approved by the Institutional Review Board for Human Studies at the University Hospital RWTH Aachen (EK 332/19) and all investigations were performed in accordance with the ethical standards laid down in the Declaration of Helsinki. Written informed consent was obtained from all patients prior to inclusion in the study. The study was registered with the German Clinical Trials Register (DRKS00019055).

\section{Patients}

All patients filling a prescription for an inhaler (corticosteroids or bronchodilators) were asked to participate in the study. Patients were asked about the underlying disease regarding the inhaled medication, if they had been trained on inhaler use before, and whether they knew how to use the inhaler correctly.

\section{Inhalation Technique Training}

After provision of written consent, patients were asked whether they knew how to use their inhalation device correctly and were asked to demonstrate the inhalation technique to a member of the study team using a placebo-containing version of their regular inhaler. Inhalation technique was rated using specific checklists, which are available for different inhalation devices in two languages (German and English). ${ }^{9}$ If inhalation technique was correct, no further intervention was undertaken. Patients with at least one mistake during their demonstration were shown a short video sequence on a tablet computer demonstrating the correct technique. ${ }^{8}$ After viewing the video, patients were asked to re-demonstrate their inhalation technique and the performance was rated again according to the specific checklist. ${ }^{13}$ If the patient still did not use the inhaler correctly, inhaler technique was demonstrated by a member of the study team.

\section{Statistical Analysis}

Statistical analysis was performed using GraphPadPrism (GraphPad Software, La Jolla, USA). Unless otherwise stated, all data are presented as mean \pm standard deviation (SD) or as median [interquartile range] after testing for normal distribution (Kolmogorov-Smirnov test). A twogroup comparison was performed using the Wilcoxon signed rank test for non-normally distributed data. Preand post-interventional measurements were compared using the Wilcoxon matched pair signed rank test. The median and the interquartile range (IQR) is given for nonnormally distributed data. The Fisher's exact test, the Chisquare test or the Chi-square test for trend were used for categorical data. Statistical significance was defined as a p-value $<0.05$.

\section{Results}

A total of $n=229$ patients were included in the study. The study flow chart is shown in Figure 1, patient characteristics are summarized in Table 1. Most patients $(n=219$; $96.6 \%$ ) stated that they had received training on inhaler use previously and that they know the correct inhalation technique ( $\mathrm{n}=195 ; 85.2 \%)$.

Correct inhalation technique was observed in $n=64$ (27.9\%) patients whereas $n=165(72.1 \%)$ patients did not use their inhalator correctly. The mistakes most commonly made were insufficient or no exhalation before inhaling (45.0\%), followed by a too short/absent breath-hold after inhalation (41.5\%). Details comparing patients with correct and faulty inhalation technique are given in Table 2. There were no significant differences in terms of age, sex, diagnosis for the prescription of an inhaler, or type of inhaler device between patients with correct and incorrect inhaler use. However, the proportion of patients which had been trained on inhaler use previously tended to be higher among patients with correct inhalation technique (100\% vs $93.9 \%$; 


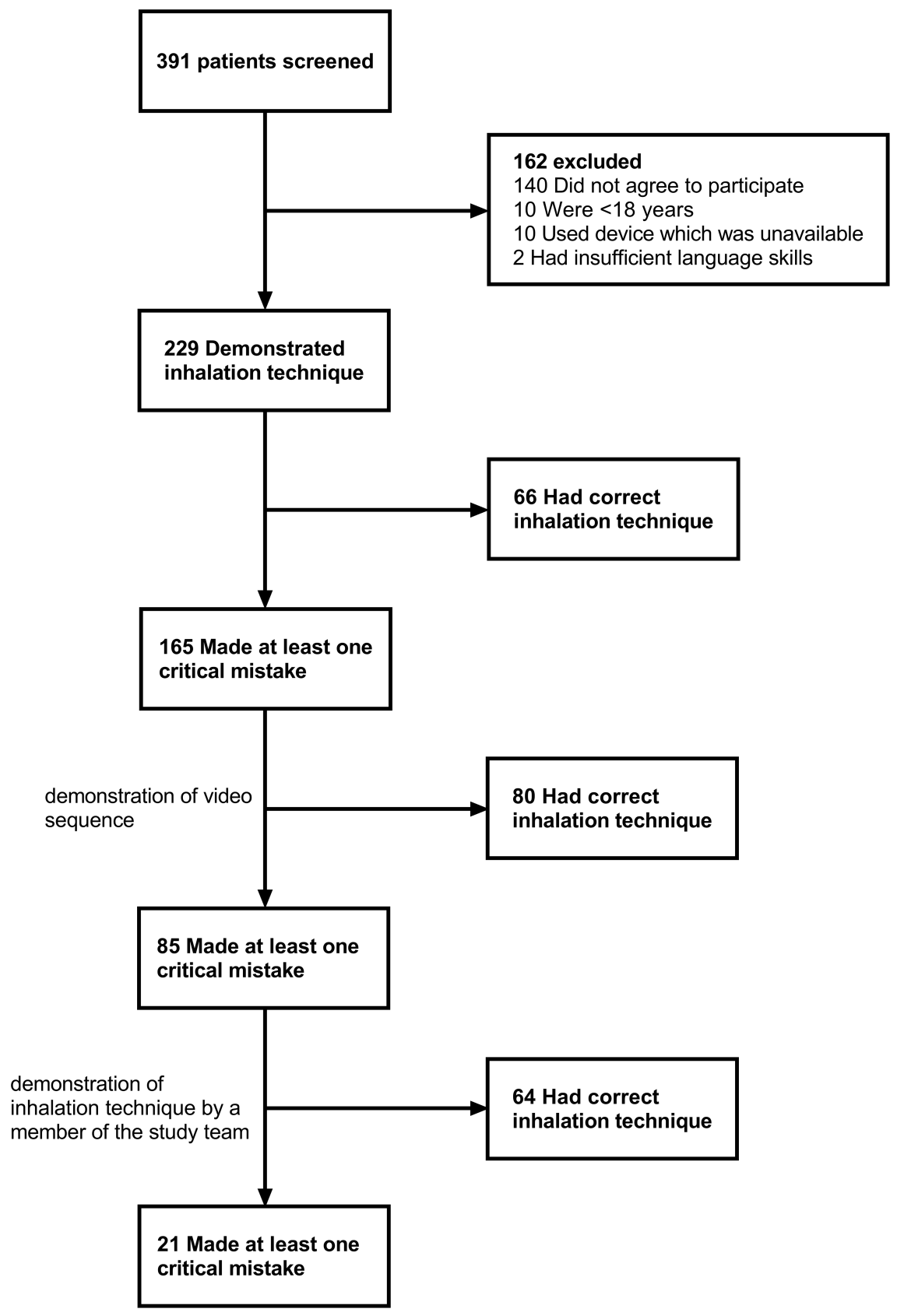

Figure I Study flow chart.

$\mathrm{p}=0.0656$ ), and a higher proportion of patients in the group with correct inhalation technique stated that they knew who to use the inhaler correctly $(95.3 \%$ vs $81.2 \% ; p=0.0065)$. In addition, patients with correct inhaler technique had been using their inhaler for a longer time period compared to patients with faulty technique $(12.5[5 ; 26.75]$ vs 5 [1; 11.75] years; $p<0.0001)$.

After viewing the video training material, patients with faulty inhalation technique at baseline $(\mathrm{n}=165)$ made significantly less mistakes $(1[0 ; 1]$ vs $2[1.5 ; 3] ; \mathrm{p}<0.0001)$ and $\mathrm{n}=80(48.5 \%)$ of these patients demonstrated correct inhaler use now (Figure 2A and B). When patients who had still made at least one critical mistake after having watched the video $(n=85)$ were instructed by a member of the study team $\mathrm{n}=64(75.3 \%)$ were able to demonstrate correct inhaler technique afterward (Figure 2B).

\section{Discussion}

The present study has shown that less than $30 \%$ of patients filling a script for an inhaler in a community 
Table I Patient Demographic Data

\begin{tabular}{|l|l|}
\hline & $\begin{array}{l}\text { Patients } \\
\text { (n=229) }\end{array}$ \\
\hline $\begin{array}{l}\text { Age, years } \\
\text { Male, } \mathbf{n}\end{array}$ & $\begin{array}{l}54.9[39.6 ; 65.2] \\
104(45.4)\end{array}$ \\
\hline $\begin{array}{l}\text { Indication for inhaled therapy, } \mathbf{n} \\
\text { COPD }\end{array}$ & $61(26.6)$ \\
Asthma & $109(47.6)$ \\
Other/unknown & $59(25.8)$ \\
\hline $\begin{array}{l}\text { Type of inhaler device, } \mathbf{n} \\
\text { Dry powder } \\
\text { Metered dose }\end{array}$ & $81(35.4)$ \\
Soft mist & $145(63.3)$ \\
\hline $\begin{array}{l}\text { Patient training and skill, } \mathbf{n} \\
\text { Had previously received training on inhaler use } \\
\text { Stated that they knew correct inhalation } \\
\text { technique }\end{array}$ & $219(96.6)$ \\
\hline
\end{tabular}

Notes: Data are presented as median [interquartile range] or number of patients (percentage).

Abbreviation: COPD, chronic obstructive pulmonary disease.

pharmacy were able to use their device correctly though almost all patients stated to have received training on inhaler use before. Simple viewing of a short tutorial video significantly improved inhalation technique. Nevertheless, more than half of the patients still made at least one critical mistake after having watched the video.
The considerable rate of mistakes when handling inhalers is in accordance with numerous studies although most patients stated that they had received training on inhaler use previously. ${ }^{4,8,9}$ Of note incorrect inhalation technique was even more common than in patients treated in a respiratory outpatient clinic based at a tertiary hospital most likely related to different patient populations investigated in the two studies. ${ }^{9}$ In contrast to earlier data the prevalence of incorrect inhalation technique was not higher in older patients which might be due to a younger population in the current study. ${ }^{4,9}$ Interestingly, patients with correct inhaler use had been using their inhalers for a longer period of time which should be taken into account when switching a patient's therapy to a new inhaler type. ${ }^{13}$

Several factors contribute to incorrect inhaler device use, eg, the complexity of the inhalation procedure, a lack of device-specific instructions provided to patients, and a lack of ongoing training opportunities highlighting the importance of patient education. ${ }^{14}$ In accordance, international guidelines recommend to demonstrate proper inhalation technique to patients and to regularly re-check whether patients continue to use their inhaler correctly though it is not known which strategy is the most efficient. ${ }^{1,2}$ Nevertheless, explaining correct inhalation technique to each patient can be time-consuming for health care providers and therefore might be overlooked during busy daily practice, which is confirmed by a previous study

Table 2 Characteristics of Patients with Correct versus Incorrect Inhalation Technique

\begin{tabular}{|c|c|c|c|}
\hline & \multicolumn{2}{|c|}{ Inhalation Technique } & \multirow[t]{2}{*}{ p-value } \\
\hline & Correct $(n=64)$ & Incorrect $(n=165)$ & \\
\hline Age, years & $53.6[29.5 ; 63.4]$ & $55.4[40.7 ; 66.0]$ & $\mathrm{N} / \mathrm{A}$ \\
\hline Male, $\mathrm{n}$ & $26(40.6)$ & $78(47.3)$ & $0.3792^{\mathrm{a}}$ \\
\hline \multicolumn{4}{|l|}{ Diagnosis } \\
\hline COPD & $13(20.3)$ & $48(29.1)$ & $0.1494^{c}$ \\
\hline Asthma & $37(57.8)$ & $72(43.6)$ & \\
\hline Other/unknown & $14(2 \mid .9)$ & $45(27.3)$ & \\
\hline \multicolumn{4}{|l|}{ Type of inhaler device, $n$} \\
\hline Dry powder & $24(37.5)$ & $57(34.5)$ & $0.8884^{c}$ \\
\hline Metered dose & $39(60.9)$ & $106(64.2)$ & \\
\hline Soft mist & I (I.6) & $2(1.2)$ & \\
\hline \multicolumn{4}{|l|}{ Patient training and skill, $n$} \\
\hline Had previously received training on inhaler use & $64(100)$ & 155 (93.9) & $0.0656^{\mathrm{a}}$ \\
\hline Stated that they knew correct inhaler technique & $61(95.3)$ & $134(8 \mid .2)$ & $0.0065^{\mathrm{a}}$ \\
\hline Have been using device since, years & $12.5[5 ; 26.75]$ & $5[\mathrm{I} ; \mathrm{II} .75]$ & $<0.0001^{b}$ \\
\hline
\end{tabular}

Notes: Data are presented as median [interquartile range] or number of patients (percentage). ${ }^{\mathrm{a}} \mathrm{Fisher}$ 's exact test; ${ }^{\mathrm{b}}$ Unpaired $t$-test; ${ }^{\mathrm{c}} \mathrm{Chi}$-square test. Abbreviation: COPD, chronic obstructive pulmonary disease. 

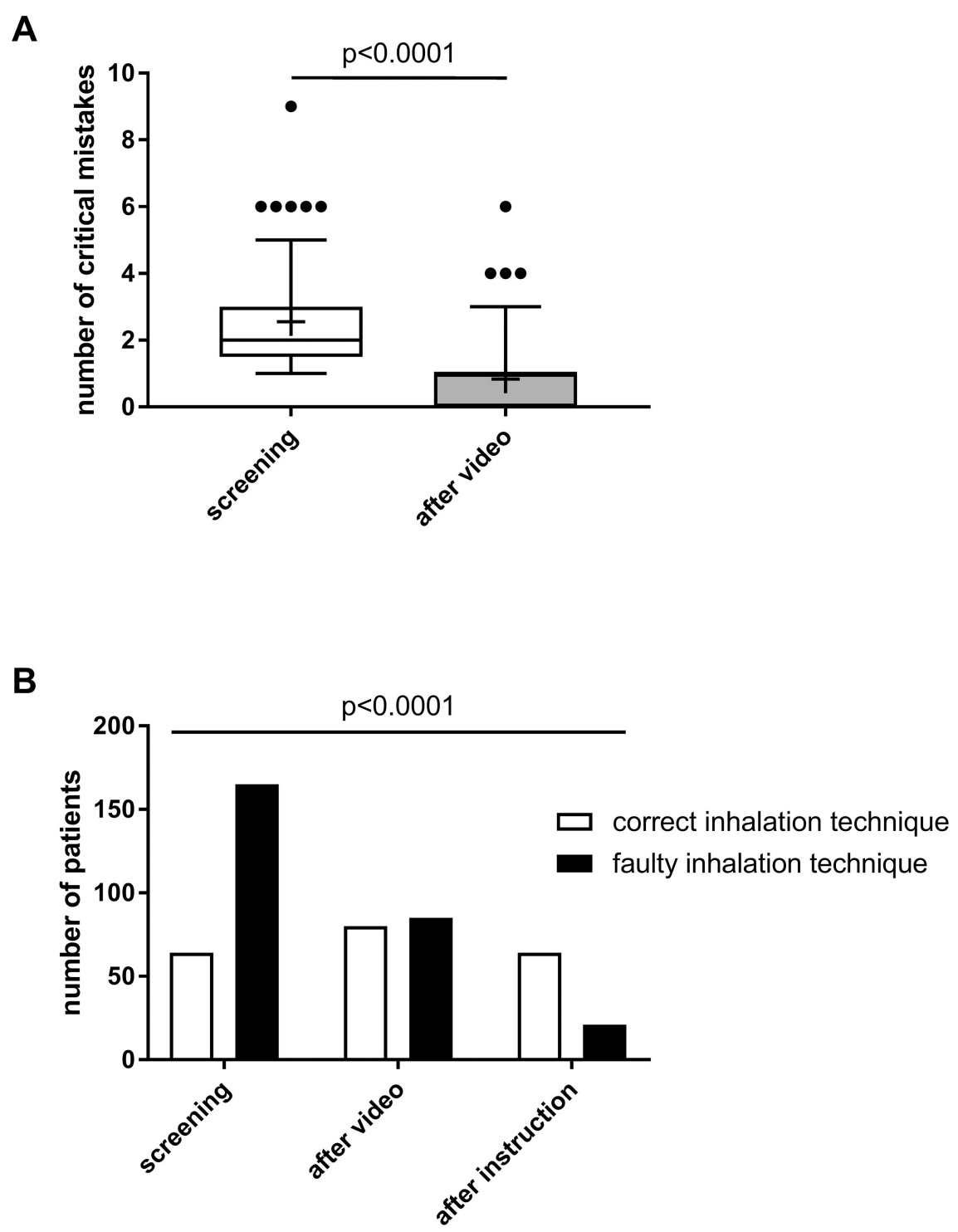

Figure 2 Inhalation technique. (A) The number of critical errors at screening and after having watched the video training material is given ( $\mathrm{n}=165$ ). Boxes represent interquartile range, whiskers demonstrate $5-95 \%$ percentile, means are indicated by the + symbol. (B) Number of patients with correct and faulty inhalation technique at screening $(n=229)$, after having watched video training material $(n=165)$, and after instruction by a member of the study team $(n=85)$.

demonstrating that patient education in terms of correct inhaler usage is not routinely performed in most community pharmacies. ${ }^{15}$ The videos used in our present study can be understood by most patients and significantly improve inhalation technique under different settings. ${ }^{9,11,16}$ Accordingly, data from previous studies suggest that education of inhaler technique by video leads to an objective improvement and can even be as effective as instruction in person. ${ }^{17-19}$ However, as there was still a considerable number of patients not being able to use their inhaler correctly after having watched the video, assessment of the inhalation technique by a qualified person is still indispensable. Furthermore, some patients are not mentally or physically capable of using inhalers correctly even after repeated training. Under such circumstances, the prescription of a nebulizer instead of an inhaler seems to be a reasonable approach. Besides the underlying disease must be taken into account when instructing patients in correct inhaler use, as many patients suffering from severe COPD cannot inhale deeply and then breath hold for longer than 4 seconds. These patients should be taught to slowly exhale fully so that they can inhale over a few seconds and hold their breath for at least 4 seconds afterwards.

To ensure the correct usage of inhalers over time most patients require repeated training and reinforcement as confirmed by several studies and recommended by national and international guidelines, although persistence of the training effect over time is suggested by 
our previous study. ${ }^{1,2,9,20-22}$ Moreover, repeated educational interventions have even been demonstrated to improve medication adherence, disease control, and quality of life in patients suffering from obstructive airway diseases. $^{22-24}$ The videos used in the present study are freely available online, giving health care providers, eg, office and hospital-based respiratory physicians, general practitioners, or community pharmacists, the opportunity to repeatedly demonstrate the videos to patients. In addition, patients with Internet access can watch the videos whenever and wherever they want. Taken together the videos might be an effective tool to support and sustain the effects of inhaler training.

This study has some limitations that need be mentioned: firstly, the study was performed in a single community pharmacy which could induce bias due to patient selection; secondly, information about the indication for inhaled therapies were obtained from patients only and might therefore be inaccurate.

\section{Conclusion}

In summary we were able to show that short videos demonstrating correct inhaler use can be used to improve patients' inhalation technique in a community pharmacy though assessment by a qualified person is still necessary. Further studies are warranted to investigate whether such an intervention can improve clinical outcome parameters.

\section{Acknowledgments}

The authors thank all the patients who took part in the study and the staff of the Elsass Apotheke Aachen for their help with patient recruitment.

\section{Disclosure}

The authors report no conflicts of interest in this work.

\section{References}

1. Global Initiative for Chronic Obstructive Lung Disease. 2020 Report: global strategy for prevention, diagnosis and management of COPD; 2019. Available from: http://www.goldcopd.org. Accessed December 15, 2020.

2. Global Strategy For Asthma Management And Prevention; 2020. Available from: https://ginasthma.org/. Accessed December 15, 2020.

3. Capanoglu M, Dibek Misirlioglu E, Toyran M, Civelek E, Kocabas CN. Evaluation of inhaler technique, adherence to therapy and their effect on disease control among children with asthma using metered dose or dry powder inhalers. J Asthma. 2015;52(8):838-845. doi:10.3109/02770903.2015.1028075

4. Melani AS, Bonavia M, Cilenti V, et al. Inhaler mishandling remains common in real life and is associated with reduced disease control. Respir Med. 2011;105(6):930-938. doi:10.1016/j.rmed.2011.01.005
5. Ahn JH, Chung JH, Shin KC, et al. Critical inhaler handling error is an independent risk factor for frequent exacerbations of chronic obstructive pulmonary disease: interim results of a single center prospective study. Int $J$ COPD. 2019;14:2767-2775. doi:10.2147/ COPD.S234774

6. Molimard M, Raherison C, Lignot S, et al. Chronic obstructive pulmonary disease exacerbation and inhaler device handling: real-life assessment of 2935 patients. Eur Respir J. 2017;49 (2):1601794. doi:10.1183/13993003.01794-2016

7. Saunders KB. Misuse of inhaled bronchodilator agents. Br Med J. 1965;1(5441):1037-1038. doi:10.1136/bmj.1.5441.1037

8. Sanchis J, Gich I, Pedersen S. Aerosol Drug Management Improvement Team (ADMIT). Systematic review of errors in inhaler use: has patient technique improved over time? Chest. 2016;150 (2):394-406. doi:10.1016/j.chest.2016.03.041

9. Müller T, Müller A, Hübel C, et al. Optimizing inhalation technique using web-based videos in obstructive lung diseases. Respir Med. 2017;129:140-144. doi:10.1016/j.rmed.2017.06.009

10. Knipel V, Criée CP, Windisch W. [Correct inhalation therapy: instructions provided by Internet-based video screens. An initiative of the German Airway League]. Pneumologie. 2013;67(3):157-161. German.

11. Windisch W, Schwarz SB, Magnet FS, et al. Using web-based videos to improve inhalation technique in COPD patients requiring hospitalization: a randomized controlled trial. PLoS One. 2018;13(10): e0201188. doi:10.1371/journal.pone. 0201188

12. Hesso I, Gebara SN, Kayyali R. Impact of community pharmacists in COPD management: inhalation technique and medication adherence. Respir Med. 2016;118:22-30. doi:10.1016/j.rmed.2016.07.010

13. Bjermer L. The importance of continuity in inhaler device choice for asthma and chronic obstructive pulmonary disease. Respiration. 2014;88(4):346-352. doi:10.1159/000363771

14. Takaku Y, Kurashima K, Ohta C, et al. How many instructions are required to correct inhalation errors in patients with asthma and chronic obstructive pulmonary disease? Respir Med. 2017;123:110-115. doi:10.1016/j.rmed.2016.12.012

15. Mickle TR, Self TH, Farr GE, et al. Evaluation of pharmacists' practice in patient education when dispensing a metered-dose inhaler. DICP. 1990;24(10):927-930. doi:10.1177/106002809002401003

16. Luley M-C, Loleit T, Knopf E, et al. Training improves the handling of inhaler devices and reduces the severity of symptoms in geriatric patients suffering from chronic-obstructive pulmonary disease. $B M C$ Geriatr. 2020;20(1):398. doi:10.1186/s12877-020-01804-4

17. Locke ER, Thomas RM, Woo DM, et al. Using video telehealth to facilitate inhaler training in rural patients with obstructive lung disease. Telemed J E Health. 2019;25(3):230-236. doi:10.1089/ tmj.2017.0330

18. Self TH, Brooks JB, Lieberman P, Ryan MR. The value of demonstration and role of the pharmacist in teaching the correct use of pressurized bronchodilators. Can Med Assoc J. 1983;128 (2):129-131.

19. Press VG, Arora VM, Kelly CA, et al. Effectiveness of virtual vs in-person inhaler education for hospitalized patients with obstructive lung disease: a randomized clinical trial. JAMA Netw open. 2020;3 (1):e1918205. doi:10.1001/jamanetworkopen.2019.18205

20. Buhl R, Bals R, Baur X, et al. Guideline for the diagnosis and treatment of asthma: guideline of the German Respiratory Society and the German Atemwegsliga in cooperation with the Paediatric Respiratory Society and the Austrian Society of Pneumology. Pneumologie. 2017;71(12):849-919.

21. Vogelmeier C, Buhl R, Burghuber O, et al. Guideline for the diagnosis and treatment of COPD patients: issued by the German Respiratory Society and the German Atemwegsliga in cooperation with the Austrian Society of Pneumology | leitlinie zur Diagnostik und Therapie von Patienten mit chronisch obs. Pneumologie. 2018;72 (4):253-308. 
22. Plaza V, Peiró M, Torrejón M, et al. A repeated short educational intervention improves asthma control and quality of life. Eur Respir J. 2015;46(5):1298-1307. doi:10.1183/13993003.00458-2015

23. Takemura M, Mitsui K, Itotani R, et al. Relationships between repeated instruction on inhalation therapy, medication adherence, and health status in chronic obstructive pulmonary disease. Int J Chron Obstruct Pulmon Dis. 2011;6:97-104. doi:10.2147/ COPD.S16173
24. Takemura M, Kobayashi M, Kimura K, et al. Repeated instruction on inhalation technique improves adherence to the therapeutic regimen in asthma. $J$ Asthma. 2010;47(2):202-208. doi:10.3109/0277090090 3581692

\section{Publish your work in this journal}

The International Journal of COPD is an international, peer-reviewed journal of therapeutics and pharmacology focusing on concise rapid reporting of clinical studies and reviews in COPD. Special focus is given to the pathophysiological processes underlying the disease, intervention programs, patient focused education, and self management protocols. This journal is indexed on PubMed Central, MedLine and CAS. The manuscript management system is completely online and includes a very quick and fair peer-review system, which is all easy to use. Visit http://www.dovepress.com/testimonials.php to read real quotes from published authors.

Submit your manuscript here: https://www.dovepress.com/international-journal-of-chronic-obstructive-pulmonary-disease-journal 